\title{
EFEITOS GLOBAIS DA TEMPERATURA E DA PRECIPITAÇÃO EM TELHADOS VERDES
}

\author{
OHNUMA JUNIOR, Alfredo Akira - akira@uerj.br \\ Universidade do Estado do Rio de Janeiro / UERJ
}

MARQUES, Marcia - marciam@uerj.br

Universidade do Estado do Rio de Janeiro

PIMENTEL DA SILVA, Luciene - luciene.pimenteldasilva@gmail.com
Universidade do Estado do Rio de Janeiro

\begin{abstract}
RESUMO: O efeito direto da temperatura, da radiação solar e da precipitação nas cidades pode provocar impactos como as ilhas de calor e as inundações urbanas. 0 objetivo deste artigo é avaliar a influência de fatores e elementos meteorológicos no comportamento de telhados verdes instalados em mais de 100 países a partir da classificação climática de Köppen-Geiger. Foram mapeados mais de 170 artigos científicos publicados em periódicos nacionais e internacionais com estudos experimentais e de modelagem aplicados em telhados verdes. Os resultados indicam predominância de $70 \%$ de estudos com telhados verdes em áreas de clima temperado, sendo $65 \%$ das pesquisas relacionadas ao conforto térmico e à quantidade e qualidade da retenção do escoamento superficial. As pesquisas revelam relativa influência de fatores geográficos que condicionam os elementos climáticos de temperatura e precipitação na capacidade de retenção do escoamento superficial em telhados verdes, entretanto são capazes de condicionar sistemas de arrefecimento à medida que delimitam efeitos térmicos provocados por variações de temperatura presentes nas superfícies de telhados verdes.
\end{abstract}

Palavras- chaves: telhados verdes, conforto térmico, retenção de águas pluviais, classes climáticas.

\section{GLOBAL EFFECTS OF TEMPERATURE AND PRECIPITATION IN GREEN ROOFS}

ABSTRACT: The effect of temperature, solar radiation and rainfall directly affects the cities, especially densely occupied areas, with impacts on the formation of heat islands and urban flooding. The purpose of this article is to evaluate the influence of factors and meteorological elements in the behavior of green roofs installed in more than 100 countries from the climatic classification of Köppen-Geiger. They were mapped more than 170 scientific papers published in national and international journals with experimental and modeling studies applied on green roofs. The results indicate a predominance of $70 \%$ of studies with green roofs in temperate areas, $65 \%$ of research related to thermal comfort and the quantity and quality of runoff retention. The researches reveal a relative influence of geographic factors that condition the climatic elements of temperature and precipitation in the capacity of runoff retention in green roofs, however, they are able to condition cooling systems as they delimit thermal effects caused by temperature variations present in surfaces green roof.

Keywords: green roof, thermal confort, rainwater retention, climate classes.

\section{INTRODUÇÃO}


De forma geral, assim como nos métodos de avaliação da classificação climática Köppen-Geiger, as pesquisas com telhados verdes baseiam-se fundamentalmente da avaliação da influência de três elementos meteorológicos básicos: (a) temperatura, (b) radiação solar e (c) precipitação. No telhado verde, as publicações relativas ao item (a) investigam possibilidades de melhoria do conforto térmico interno nas edificações para regular a temperatura dos ambientes com menos flutuações ao longo de períodos sazonais (LIU, 2003). Ao regular as flutuações térmicas sobre a superfície externa do telhado verde, eleva-se a condutividade térmica fornecida essencialmente pelo substrato, o que favorece o arrefecimento dos espaços situados abaixo do telhado durante o verão e a garantia de temperaturas mais agradáveis no inverno (NIACHOU et al., 2001). Em estudo realizado na cidade de São CarlosSP, Brasil, com características de clima equatorial de classificação KöppenGeiger Aw, o telhado verde se mostrou capaz de reduzir a temperatura ambiente em até $16^{\circ} \mathrm{C}$ em relação ao telhado convencional em determinas épocas do ano (ANDRADE e RORIZ, 2007). Na análise de desempenho térmico e energético de várias espécies de vegetação plantadas em telhado verde, na cidade de Saint-Pierre, Sul da ilha de Reunion Island, de clima tropical úmido com classificação Köppen-Geiger Af, também houve decréscimo nas flutuações de temperatura no verão, onde cada planta contribuiu para a baixa troca de fluxo de calor através do telhado verde (MORAU et al., 2012). Ao expor o telhado verde em localidades distintas de classificação climática, a partir de dados de simulação hidráulica-hidrológica, o efeito da vegetação na temperatura de coberturas, sobretudo em áreas urbanas, foi maior em climas quentes e secos (ALEXANDRI e JONES, 2008). Há poucos estudos com dados que possam compatibilizar o efeito global de elementos climáticos em estudos de experimentos locais com telhados verdes.

Do efeito da energia radiante emitida pelo Sol, as propriedades biofísicas relacionadas à vegetação e a camada de substrato de solo permitem ao telhado verde uma elevada capacidade de dissipar a energia, absorvendo a radiação solar em dias ensolarados (JIM e TSANG, 2011). A influência da radiação solar como segundo elemento meteorológico capaz de proporcionar efeitos no telhado verde, associada à evapotranspiração e outros processos fisiológicos, como a fotossíntese, também afeta a performance na capacidade de obter maior resistência térmica na cobertura (ALCAZAR e BASS, 2005 apud MORAU, 2012).

O estudo das condições de avaliação do escoamento sub-superficial no telhado verde está fundamentalmente sob influência direta do elemento meteorológico da precipitação. De forma geral, as publicações revelam resultados da influência deste elemento tanto nas perspectivas de avaliação quantitativa, como também qualitativa do escoamento em telhados verdes, especialmente em áreas urbanas. O impacto do aspecto quantitativo tem como objetivo geral reduzir ou retardar o volume de runoff, na capacidade de retenção do volume precipitado. Esse efeito de amenizar o runnoff consiste do armazenamento das águas pluviais na camada do substrato e liberação de forma distribuída do excesso no decorrer do tempo. As investigações observam eventos monitorados com capacidade de retenção do escoamento no telhado verde, no entanto uma das características de influência na capacidade de reduzir ou amortecer o volume escoado, além da umidade antecedente do solo, é a condição climática local (TASSI et al., 2014). 
Qualitativamente, os estudos investigam a influência de diferentes composições de substratos e inúmeras espécies de plantas, tanto em telhados verdes intensivos como extensivos, na capacidade de retenção de poluentes para melhoria na qualidade do efluente (runoff) em áreas urbanas (BERNDTSSON et al., 2009). Parâmetros físico-químicos, metais e nutrientes são analisados para avaliar o desempenho do sistema em diferentes regiões na qualidade da água após a retenção pelo substrato (VIJAYARAGHAVAN e JOSHI, 2014; HARPER et al., 2014; GREGOIRE e CLAUSEN, 2011).

A influência dos elementos meteorológicos no clima, mais precisamente a temperatura e a precipitação foram estudadas pela primeira vez em 1900 por Wladimir Köppen (KÖPPEN, 1884) e atualizada por Rudolf Geiger em 1961, de modo a classificar às condições do clima nas diferentes regiões da superfície terrestre. A atualização do mapa foi baseada essencialmente em dados observados de temperatura e precipitação no período entre o ano 1951 e 2000 (RUBEL e KOTTEK, 2010). Mundialmente, a classificação climática KöppenGeiger é reconhecida não somente por retratar o que há de mais atual nas condições climáticas observadas, como também para avaliar as tendências globais do clima e projeção de cenários de mudanças climáticas. Embora esses autores tenham como objetivo investigar a série histórica de dados de precipitação e temperatura para avaliar as mudanças no clima desde 1900, os mapas atuais de classificação climática podem ser válidos para estudos de temas que utilizam basicamente do mesmo elemento meteorológico, como a temperatura e a precipitação. Os benefícios da aplicação de telhados verdes, por exemplo, apresentam-se em fontes de pesquisa de diferentes regiões de classificação climática Köppen-Geiger. A maioria dos estudos envolve a aplicação de telhados verdes em escala isolada ou pontual, de modo que não expõem a influência das classes climáticas conhecidas nos benefícios da aplicação de telhados verdes.

O objetivo deste trabalho é avaliar a influência da classificação KöppenGeiger nos estudos de variação térmica, retenção do escoamento e balanço energético de telhados verdes monitorados em mais de 170 locais, agrupados em 28 países de diferentes características climáticas.

\section{METODOLOGIA}

Duas fontes principais de pesquisa foram consultadas para busca de periódicos nacionais e internacionais: o modelo acadêmico do Google Scholar (http://scholar.google.com.br/) e a renomada fonte de pesquisa científica internacional disponível no site da Science Direct (http://www.sciencedirect.com/), com artigos pesquisados na íntegra até dezembro de 2014. Inicialmente, as seguintes palavras-chave foram utilizadas: greenroof, green roof, vegetated roof, telhado verde e cobertura verde. Também foram pesquisadas palavras afins (figura 1), como: conforto térmico (thermal comfort), qualidade do escoamento (runoff quality), retenção do escoamento (stormwater retention), substrato (substrate), espécies (species) e energia (energy). Foram considerados ainda artigos de autores que investigaram demais influências na implantação do telhado verde, como: qualidade do ar (air quality), conforto acústico (acoustic comfort), projetos sociais (social project) e análise do ciclo de vida (life cycle cost). Os assuntos foram compartilhados à medida que os trabalhos investigaram no mesmo 
experimento mais de um assunto, como: na apresentação de resultados que contribuíram na análise do volume de retenção do escoamento (stormwater retention) e ao mesmo tempo na análise da qualidade do volume de escoamento (runoff quality).

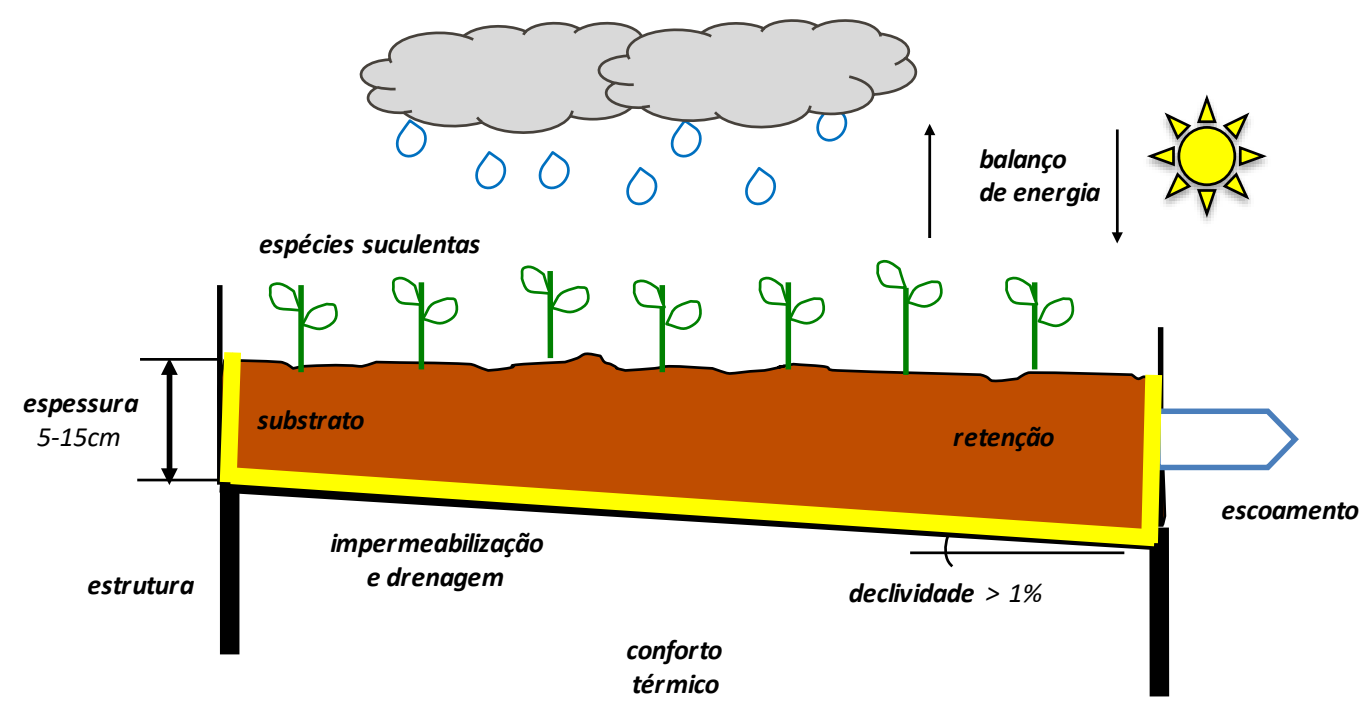

Figura 1 - Termos de indexação gerais em fontes de pesquisa de telhados verdes. Fonte: OHNUMA JR, et al. (2014). Org. dos Autores.

Ao todo, foram analisados cerca de 150 artigos, sendo a maioria de periódicos internacionais. A maioria das publicações apresentam a cidade ou local de implantação do telhado verde, mas não indicam as coordenadas geográficas e a classificação climática correspondentes. Para obter essas informações, utilizou-se a referência de RUBEL e KOTTEK (2010), que consiste de atualizar a definição de cada classe climática principal, ordem de precipitação e temperatura, baseada em dados subjacentes disponíveis no link http://koeppen-geiger.vu-wien.ac.at/. A partir de arquivo de extensão .KMZ, elaborado por Wilkerson, M. Scott e Wilkerson, M. Beth, (2010), utilizou-se o aplicativo Google Earth para identificação dos pontos amostrados, com escala da ordem de 0.5 graus latitude e longitude e resolução temporal mensal no período entre os anos 1951 e 2000 de dados observados de precipitação e temperatura. Esses dois conjuntos de dados globais correspondem às observações climáticas selecionadas para calcular o mapa desejado. O primeiro conjunto de dados, fornecido pela Climatic Research Unit (CRU) ou Unidade de Pesquisa Climática da University of East Anglia (MITCHELL e JONES, 2005), disponibiliza dados observados mensais de estações meteorológicas composta por nove variáveis climáticas, sendo apenas a temperatura considerada no estudo, com abrangência de áreas de terra globais, exceto a Antártida. O segundo conjunto de dados, fornecidos pela Global Precipitation Climatology Centre (GPCC) ou Centro de Climatologia e Precipitação Global, do Serviço Meteorológico Alemão, informa dados de precipitação entre os anos 1901 e 2007 de estações localizadas em áreas de terra globais, exceto Groenlândia e Antártida. A maior parte dos serviços meteorológicos e hidrológicos do mundo, bem como os anfitriões da base de dados globais de precipitação, a CRU, a Global Historical 
Climatology Network (GHCN), da National Climatic Data Center (NCDC), e a Food and Agriculture Organization (FAO), da United Nations, também contribuíram para os dados de precipitação da GPCC.

Baseado no esquema de Köppen-Geiger, o modelo atualizado apresenta a descrição da classificação climática por um código associado de três letras: (1) primeira letra: maiúscula e apresenta as classes ou grupos principais com a característica geral do clima da região, formado pelas iniciais do alfabeto de $A$ até $E$; (2) segunda letra: minúscula para os grupos $A, C$ ou $D$ que apresenta as particularidades do regime pluviométrico e maiúscula para os grupos $B$ e $E$, sendo precipitação total anual ou temperatura média anual, respectivamente; (3) terceira letra: minúscula e indica as temperaturas médias mensais dos meses mais quentes para os grupos $C$ ou $D$ e temperatura média anual para grupo B. Os critérios utilizados na primeira e segunda letra da atualização do mapa de classificação climática de Köppen-Geiger, assim como o uso da terceira letra que apresenta a classificação baseada em dados de temperatura, encontram-se discriminados em KOTTEK et al. (2006).

Para definir a classificação climática Köppen-Geiger dos locais pesquisados com telhado verde, utilizaram-se as informações do mapa atualizado da Climatic Research Unit (CRU) de média mensal de temperatura e dados de precipitação entre 1951 e 2000 com resolução espacial de 0,5 grau de latitude e longitude. As 31 classes climáticas compõem cores diferentes, cuja decodificação das 3 letras estão descritas no mapa (KOTTEK et al., 2006).

\section{RESULTADOS E DISCUSSÕES TERMOS DE INDEXAÇÃO}

Devido a quantidade de assuntos que se inter-relacionam com o tema "telhado verde", do total das publicações analisadas, pode-se filtrar tópicos subjacentes ao tema principal, associado aos termos de indexação da figura 1. Foram identificados um total de 18 tópicos correspondentes ao tema principal, cujos assuntos se subdividem em função da metodologia adotada em cada pesquisa, como: runoff quality e stormwater retention, ambos qualificados como runoff e, posteriomente categorizados em sub-tópicos.

Independente das condições climáticas, a identificação por assuntos subjacentes revela que $65 \%$ das publicações retrataram os benefícios associados à implantação do telhado verde na análise quali-quantitativa do escoamento (runoff) e no estudo das variações térmicas (thermal). Do total das publicações de runoff, $60 \%$ delas resultaram estudos das medições quantitativas do escoamento, que consistem em observar o comportamento da retenção (retention) das águas pluviais no substrato do telhado verde a partir das lâminas de precipitação total e da redução do pico do escoamento superficial. A qualidade (quality) do escoamento após a retenção obteve representatividade de $20 \%$ do total das publicações de runoff, em função da concentração de diferentes poluentes ou parâmetros de qualidade. Na terceira posição com $12 \%$ na indexação do runoff, os estudos de modelagem (modelling) apresentaram resultados que demonstram a capacidade dos modelos testados predizer o comportamento hidráulico-hidrológico do sistema telhado verde com certa precisão em relação aos dados observados, como o uso dos modelos: GreenAmpt (CARBONE et al., 2014), SWAP (METSELLAR, 2012) e SWMS-2D (Palla et al., 2009). No geral, foram mapeadas 42 publicações relacionadas aos benefícios térmicos (thermal) proporcionado pelos telhados verdes, o que representa cerca de $28 \%$ do total das publicações. Com uso de modelagem 
(modelling), o desempenho térmico foi calculado em 07 estudos com modelos baseados em: equações diferenciais (ALEXANDRI e JONES, 2007), equação de Penman-Monteith (OULDBOUKHITINE et al., 2010), teorias de propagação de ondas eletromagnéticas (HE e JIM, 2010), etc.

Os outros temas responsáveis por $35 \%$ das publicações compõem subáreas de estudos distintos associados aos telhados verdes em diferentes regiões climáticas e descrição correspondente, como:

- substrato: composição do substrato para melhor desempenho fisiológico das espécies;

- energia: otimização e eficiência energética na edificação em função das cargas de refrigeração;

- social: barreiras de implementação da técnica, integração social e reconciliação ecológica com as necessidades humanas;

- revisão bibliográfica: revisão de literatura com enfoques regionais e de projetos sustentáveis;

- poluição do ar: capacidade do telhado verde na remoção de poluentes atmosféricos;

- acústica: atenuação do som para melhoria do conforto acústico com telhados e paredes verdes;

- espécies: manejo agronômico na seleção de espécies para garantia do equilíbrio e manutenção do ecossistema;

- custo: análise do ciclo de vida dos telhados verdes com relação custobenefício da técnica e

- retrofit: investigação sobre o potencial de readequação de sistemas retrofit's a partir da implementação de telhados verdes.

A possibilidade de remoção de gases atmosféricos pela vegetação nos telhados para mitigação das mudanças climáticas também é um sub-tema emergente associado aos benefícios em telhados verdes. $O$ aumento de áreas verdes em coberturas de edificação permite a captura e o seqüestro de carbono em áreas urbanas, sobretudo devido ao processo de fotossíntese das espécies durante o dia (RAMIREZ e BOLAÑOS-SILVA, 2012). Em um dia ensolarado típico de verão em Hong Kong, na China, a taxa de absorção de CO2 em um determinado experimento com telhado verde durante o dia foi muito maior do que a taxa de emissão de CO2 no período da noite (LI et al., 2010). No entanto, a eficiência para remoção de gases poluentes depende não somente da espécie utilizada, mas essencialmente das condições climáticas locais, sobretudo da concentração desses gases e do fluxo de ar na região.

Em menor escala de publicações, o conforto acústico e o uso de modelos hidráulicos e hidrológicos também revelam benefícios da aplicação de telhados verdes. Os resultados do efeito acústico demonstram maior absorção do som na estratificação nas camadas de substratos dos telhados verde quando comparados com telhados convencionais (PITTALUGA et al., 2011). De forma indireta, os telhados verdes têm maior potencial para reduzir o ruído em fachadas provocado pelo tráfego excessivo de veículos (RENTERGHEM et al., 2013). Os estudos de simulações com modelagem são comparados com experimentos e coleta de dados observados e referem-se tanto para avaliação da capacidade de retenção do escoamento (LOCATELLI et al., 2014), como para predizer o desempenho do arrefecimento por perda de calor latente, que está condicionada a espessura do substrato (METSELLAR, 2012). Independentemente 
das zonas climáticas, o resultado das simulações mostrou que o tipo de vegetação influencia significativamente no saldo de radiação (ZHAO et al., 2014).

\section{MAPEAMENTO DAS LOCALIDADES DE PESQUISAS COM TELHADOS VERDE}

Das 150 publicações analisadas neste artigo, 10 apresentam resultados de pesquisas realizadas com telhados verdes em mais de uma localidade, nas quais foram identificadas cerca de 170 cidades em diferentes locais com experimentos de telhados verdes, distribuídos em 28 países de todos os continentes, exceto nas calotas polares (figura 2). Com exceção dos países emergentes China e Brasil, os países desenvolvidos lideram os locais com pesquisas de telhado verde, com destaque para os Estados Unidos que individualmente concentra cerca de $1 / 4$ dos experimentos localizados em 16 estados, o que representa pouco mais de $30 \%$ do total de estados.

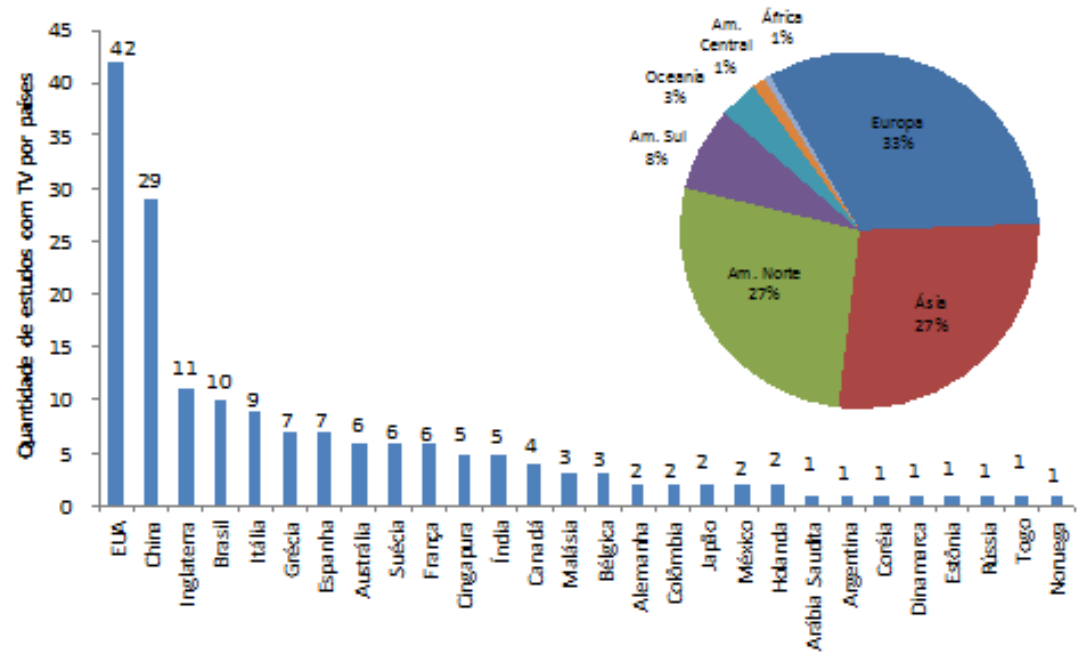

Figura 2 - Quantidade de locais com pesquisas de telhados verdes distribuídos nos países e continentes extraído de publicações de periódicos entre 2001-2014. Fonte: Artigos contabilizados dos sites do Google Scholar e Science Direct, Org. dos Autores

Por concentrar $18 \%$ das localidades com estudos de telhados verdes entre os países do globo terrestre e mais da metade dos experimentos asiáticos, a China se situa na vice-liderança da pesquisa. Na parte inferior da linha do equador, estimam-se $10 \%$ de locais com estudos de telhado verde, onde Brasil e Austrália compõem os países de maior contribuição, com 5,8\% e 3,5\%, respectivamente. Europa, Asia e América do Norte constituem continentes com quase $90 \%$ de estudos e locais de pesquisas com telhados verdes, onde as condições climáticas são classificadas de forma diferente dos pontos situados abaixo da linha do Equador. 


\section{CLASSIFICAÇÃO CLIMÁTICA KÖPPEN-GEIGER}

A representatividade nas classes climáticas é de fundamental importância para análise da influência dos elementos meteorológicos nos termos de indexação apresentados nas figuras 1 e 2, essencialmente no efeito das variações térmicas, no balanço de energia e na retenção das águas pluviais sobre as coberturas com vegetação.

Nos 170 locais identificados nesta pesquisa com telhados verdes foram associadas 14 classes climáticas correspondentes, o que representa cerca de metade das classes disponíveis no globo pelo método Köppen-Geiger e avaliadas nos experimentos com telhados verdes. O mapa atualizado de classificação climática Köppen-Geiger (RUBEL e KOTEK, 2010) da figura 3 resume o quantitativo dos principais pontos de experimentos com telhados verdes.

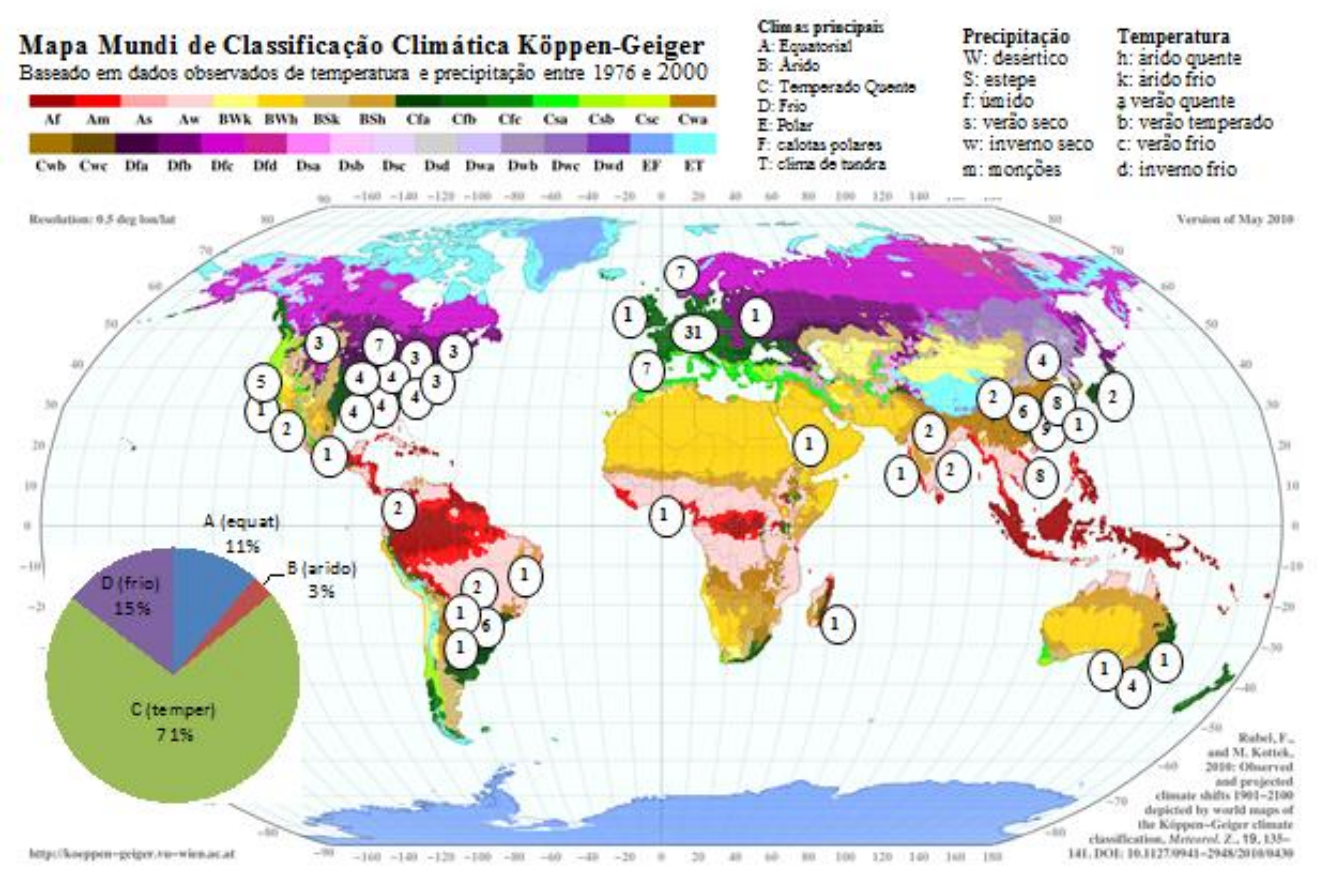

Figura 3 - Mapa mundi de classificação climática Köppen-Geiger e pontos de distribuição da quantidade de estudos com telhados verdes. Fonte: Adaptado RUBEL e KOTTEK (2010). Org. dos Autores.

Cerca de $85 \%$ dos estudos realizados com telhado verde, sob diferentes aspectos, estão localizados em regiões de clima temperado e de classificação climática grupos C e D. Estimam-se $45 \%$ das localidades em regiões de clima temperado úmido e verão quente de classificação climática Köppen-Geiger Cfa e Cfb, concentrados basicamente na Europa e leste dos Estados Unidos. As regiões de clima temperado com inverno seco e de clima frio com verão quente, classes Cwa e Dwa respectivamente, compõem os países asiáticos, especialmente a China. Com características de clima equatorial úmido, de classificação Af, países como Cingapura e Malásia, representam 5\% dos locais pesquisados com telhado verde. Regiões de clima árido, como Arábia Saudita, Arizona, nos Estados Unidos e Madras na Índia, representam 3\% dos locais com climas classificados como BWh e BSh. A maioria dos estudos infere benefícios da 
aplicação de telhados verdes para melhoria da qualidade do ambiente e da população, baseados nas condições climáticas do local.

\section{EFEITO TÉRMICO E EFEITO RUNOFF}

Em locais com climas tropicais quentes, como por exemplo em Madras, na Índia ou Togolese, na África, ambos de classificação climática Köppen-Geiger Aw, as cargas térmicas são consideradas bastante elevadas, especialmente em dias ensolarados, o que tende a provocar um ambiente desagradável no interior dos edifícios. Os ganhos de calor decorrem do efeito do aquecimento proveniente da radiação solar absorvida pela laje ou paredes, cuja transferência para o interior dos prédios eleva a temperatura ambiente. A energia consumida ou perdida no arrefecimento de um edifício considera as mudanças de cargas térmicas em paredes, vidros, infiltrações e fugas de ar renováveis. Além dos ganhos de energia provenientes da radiação solar incidente nas coberturas, há também ganhos internos do edifício, como iluminação, ocupação de ambientes, equipamentos elétricos, etc (HODO-ABALO et al., 2012).

Cidades de países com clima temperado e úmido, como Shanghai, na China, de classificação climática Köppen-Geiger Cfa apresentam redução da temperatura interna quando o telhado é composto por vegetação. O fluxo de calor sensível neste tipo de cobertura é baixo devido ao elevado fluxo de calor latente de evapotranspiração e maior radiação líquida. Estimativas indicam que variações da quantidade de perda d'água por evapotranspiração no telhado verde são bastante significativas, inclusive quando relacionadas com solo exposto, mesmo no inverno. As taxas de evapotranspiração no verão superam $3 x$ a quantidade no inverno, devido à uma maior temperatura da superfície nesse período. No mesmo estudo, o fluxo de calor sensível no telhado verde é cerca de 60 W.m-2 menor quando comparado com laje de concreto, constatado também no período noturno (TAKEBAYASHI e MORIYAMA, 2007).

Além das medições de temperatura interna no ambiente e taxas de evaporação, o conforto térmico em edificações pode ser observado pelos elementos ou materiais de cobertura que compõem o telhado e dificultam a passagem de calor por condução, cujo desempenho está relacionado com o valor da resistência térmica (RSI), cuja unidade é representada por m2.k.W-1 pelo RSI ou h.ft2.F.Btu-1 pelo R-value. Quanto maior é a resistência térmica, maior é a resistência à passagem do fluxo de calor ao interior dos ambientes (adaptado DOE, 1991).

Ressalvas particularidades de cada pesquisa, resultados indicam leve tendência de maior RSI nos telhados verdes localizados em regiões de clima equatorial tropical, classes Köppen-Geiger $A$ e $B$, em relação àqueles identificados de clima temperado classe $C$. Ainda que necessite de maior associação de parâmetros e análise dos dados, nota-se que as regiões de Cingapura, Índia e Reunion Island, consideradas de temperaturas quentes mais elevadas podem obter melhor desempenho térmico em função de maior RSI nas coberturas com vegetação do que em regiões de clima temperado com classes climáticas tipo Csa, Cwb e Cfa, como Grécia e China. Nesse sentido, instalar telhados verdes em climas quentes pode ser considerado mais adequado do que em climas frios para reduzir a demanda de energia na refrigeração do ambiente, ainda que o telhado verde possa auxiliar na redução da demanda de energia no arrefecimento de ambientes em climas temperados de classificação climática C 
(ASCIONE et al., 2013). Os dados são influenciados pela análise do balanço de energia a partir da densidade de vegetação, que pode ser obtida pela área de densidade foliar ou Leaf Area Index (LAI), de valor adimensional, sendo LAI = $\mathrm{S} / 2 \mathrm{G}$, onde $\mathrm{S}$ é a medida de área projetada de amostras de folhagem na superfície horizontal e $\mathrm{G}$ é a área de cobertura do solo (AYATA et al., 2011).

Além das condições climáticas, a profundidade da camada de substrato resulta ganhos e perdas de calor. Telhados verdes com solos profundos produzem menor ganho de calor na superfície e perda para a atmosfera, resultando um melhor desempenho térmico. Estudo realizado em Cingapura, de classificação climática Köppen-Geiger Af, demonstrou que um aumento de 10 $\mathrm{cm}$ de espessura da camada de solo seco aumenta sua resistência térmica cerca de $0,4 \mathrm{~m} 2 . \mathrm{K} . \mathrm{W}-1$. No entanto, ressalta-se que a umidade do solo influencia em grande medida as propriedades térmicas do telhado verde, com variações máximas da ordem de 0,06 m2.K.W-1 para cada aumento de $10 \mathrm{~cm}$ de espessura (WONG et al., 2003).

A tabela 1 apresenta os valores de RSI de publicações com estudos realizados em diferentes regiões de classificação climática e variações de temperatura interna correspondentes. Com exceção do trabalho de WEI (2005), com experimento realizado no inverno em Xi'An na China, todos os outros foram observados no verão. 
Tabela 1 - Variação de temperatura e retenção do escoamento superficial em edificações com telhado verde para diferentes classes climáticas. Fonte: Citada na coluna 1 Referência (Ano), Org. dos Autores.

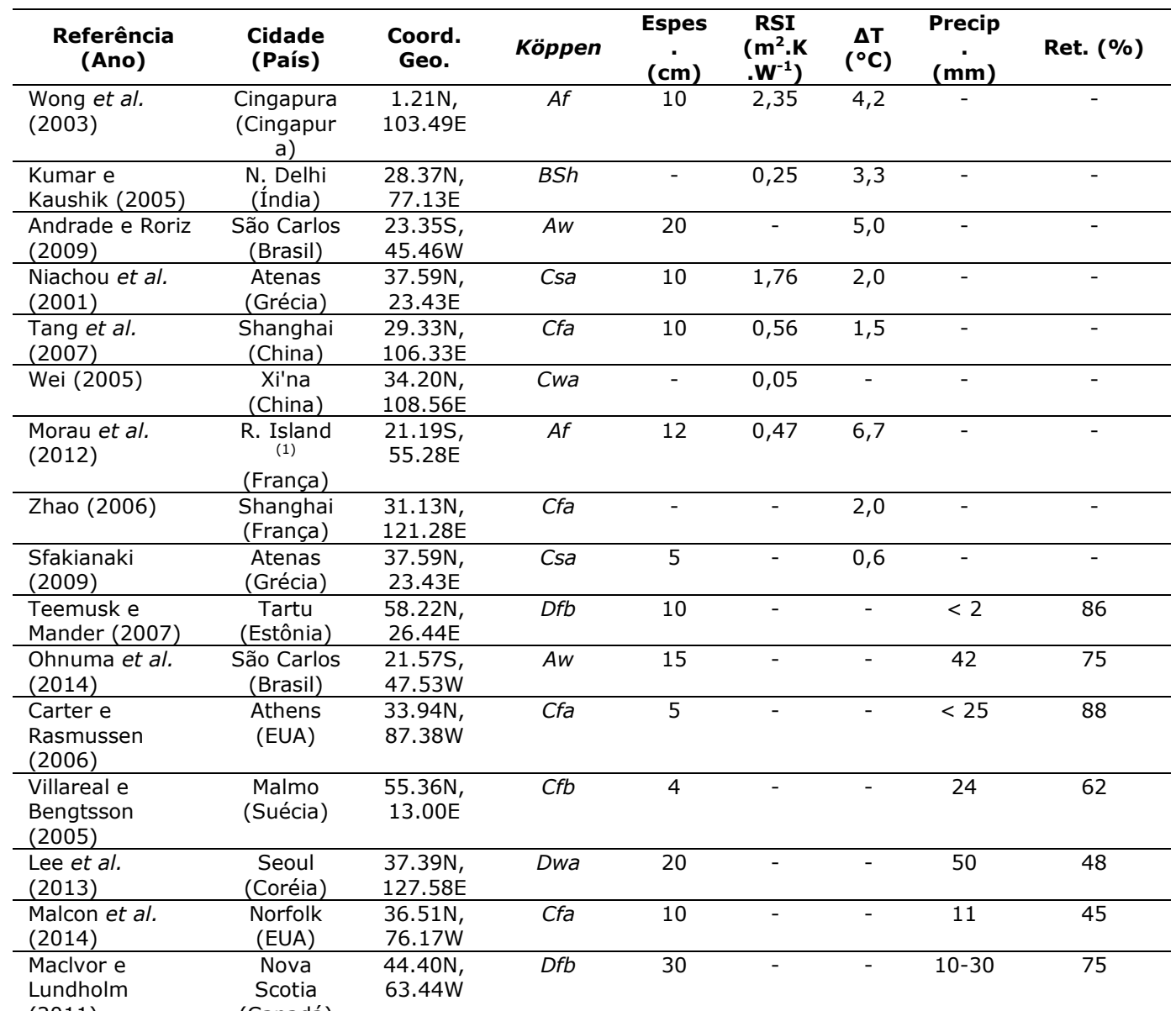

(2011) (Canadá)

NOTA: (1) Região externa do Mediterrâneo; Espes: espessura do substrato; RSI: resistência térmica; $\boldsymbol{\Delta T}$ : variação térmica em edificações; Precip: Precipitação pluviométrica e Ret: retenção do escoamento superficial.

Localizado no lado leste do Oceano Índico a ilha de Reunion Island, de domínio francês, apresenta particularidades diferentes das condições climáticas da Europa, por se situar em região externa do Mediterrâneo, com características de clima equatorial tropical úmido de classificação climática Köppen-Geiger Af. Com profundidade total de $12 \mathrm{~cm}$, sendo $8 \mathrm{~cm}$ de substrato e $4 \mathrm{~cm}$ de drenagem, a presença de vegetação no telhado situado em Reunion Island induziu a diminuição de flutuações de temperatura na ordem de $7^{\circ} \mathrm{C}$ entre a superfície e o fundo do substrato. O coeficiente de transferência de calor igual a 2,15 W.m-2.K-1 para a espécie testada Sedum, obteve a maior resistência térmica RSI de 0,47 m2.K.W-1, entre as espécies comparadas Plectranthus e Kalanchoe (MORAU et al, 2012). Em Cingapura, de mesma classificação climática Köppen-Geiger Af da ilha de Reunion Island, o efeito de resfriamento do ambiente foi confirmado com a diferença máxima de $4,2^{\circ} \mathrm{C}$ entre a superfície com vegetação e outra sem vegetação. Embora em condições distintas 
relacionadas a altura das medições, o fluxo de calor é menos sensível nas coberturas com vegetação (WONG et al., 2003).

Ainda que a variação térmica interna de $2^{\circ} \mathrm{C}$ seja considerada pequena em edificação com telhado verde na cidade de Atenas, na Grécia, de classificação climática Köppen-Geiger Csa, ou de clima mediterrâneo, após cerca de 200 medições no verão apenas $15 \%$ resultaram temperaturas internas acima de $30^{\circ} \mathrm{C}$, enquanto coberturas sem vegetação apresentaram $70 \%$ das medições (NIACHOU et al., 2001).

Ao utilizar a espécie Brachiaria humidicola em telhado na cidade de São Carlos, SP, Brasil, de classificação climática Köppen-Geiger Aw, a maior variação térmica interna obtida em comparação com telhado sem vegetação foi em torno de $5^{\circ} \mathrm{C}$. O mesmo estudo apresenta $15^{\circ} \mathrm{C}$ de diferença de temperatura superficial interna entre a laje convencional e a cobertura com vegetação (ANDRADE e RORIZ, 2007).

Das 150 publicações, praticamente 1/3 delas apresentam resultados relacionados aos aspectos quali-quantitativos do escoamento ou runoff sob 0 telhado verde, seja na capacidade de retenção pelo substrato das águas pluviais, ou na qualidade do efluente em função da concentração de determinados poluentes. Os estudos apresentam a capacidade de retenção das águas pluviais em telhados verdes extensivos em função da: classificação climática Köppen-Geiger, espessura da camada de substrato e precipitação local (tabela 1). A maioria dos substratos consistem de agregado leve, húmus e argila ou solo mineral e argila orgânica ou ardósia expandida, areia e matéria orgânica, todas com vegetação da espécie sedum, grama ou hortaliças.

Enquanto na cidade de Athens-GA, Estados Unidos, de clima temperado com classificação Köppen-Geiger Cfa, a capacidade de retenção máxima de um telhado verde foi de até $88 \%$ do volume total precipitado em 13 meses de dados observados (CARTER e RASMUSSEN, 2006), o telhado verde monitorado na cidade de São Carlos-SP, Brasil, com clima equatorial de classificação KöppenGeiger Aw, em 7 meses de observação obteve retenção máxima de $75 \%$ do total precipitado (OHNUMA et al., 2014). Regiões frias, de classificação climática grupo D, como Tartu, na Estônia, e Seoul, na Coréia do Sul, a eficiência na retenção do escoamento de $86 \%$ (TEEMUSK e MANDER, 2007) e 48\% (LEE et al., 2013), respectivamente, foi obtida para diferentes valores de precipitação e de espessura do substrato.

Os estudos publicados resultam que, muito mais que as classes climáticas e a precipitação, o volume armazenado ou retido no telhado verde depende também de outros fatores fundamentais, como: duração da precipitação para determinação da intensidade pluviométrica, espécie de plantio, período seco antecedente, composição e espessura do substrato. Os efeitos da profundidade ou espessura do substrato na capacidade de armazenamento das águas pluviais em coberturas com vegetação, para as mesmas precipitações a retenção foi de $75 \%$ para telhado verde com $15 \mathrm{~cm}$ de substrato e de $45 \%$ para espessura de $10 \mathrm{~cm}$. Embora a tabela 3 não resulte influências significativas nas lâminas de retenção em relação às diferentes classes climáticas, podem ocorrer diferenças significativas do volume retido nas estações quentes (verão) e frias (inverno), da ordem de 30\% e 67\%, respectivamente (MENTENS et al., 2006), para a mesma localidade da pesquisa, na Alemanha, de classificação climática Köppen-Geiger Cfb. No entanto, os resultados de retenção nos telhados verdes 
apresentam maior influência de parâmetros físicos do que de elementos meteorológicos.

Outro fator fundamental de influência no armazenamento das águas pluviais, independente da classificação climática local, é a declividade do telhado, que rigorosamente altera a velocidade do escoamento superficial das águas pluviais, sobretudo em solos saturados. Para determinados eventos de precipitação, a retenção diminui à medida que a declividade aumenta e a retenção é maior para baixas intensidades pluviométricas (VILLARREAL e BENGTSSON, 2005; GETTER et al., 2007). De forma similar, além do transporte de materiais do telhado verde para microdrenagem, a umidade antecedente também é fator decisivo na redução do escoamento (MORUZZI et al., 2014).

\section{OBTENÇÃO DO RUNOFF E RETENÇÃO DO ESCOAMENTO COM MODELAGEM EM TELHADOS VERDES}

Assim como na previsão de cenários na mudança do uso e ocupação do solo em áreas urbanas a partir de hidrogramas de cheias, diferentes modelos hidráulico-hidrológicos também têm sido utilizados para predizer o comportamento do sistema telhado verde em resposta aos eventos de precipitação. O modelo Soil Water Atmosphere and Plant (SWAP), cuja resposta é baseada na discretização do perfil do solo, obteve respostas entre $55 \%$ e $75 \%$ de retenção do escoamento em um telhado plano com dados meteorológicos da cidade de Wageningen, Dinamarca (METSELLAR, 2012). A partir de resultados observados, as simulações confirmam que a espessura do solo e o tipo de substrato são bastante determinantes na capacidade de retenção das águas pluviais. Incertezas no clima das cidades demonstram maiores influências na evapotranspiração, como efeito das condições de umidade do local.

O modelo HYDRUS-1D, baseado no método SCS e Equação de Richards, gerou hidrogramas significativos com retenção entre $22 \%$ e $100 \%$ dos eventos simulados, além de retardar o escoamento devido o aumento de sua duração reduzindo assim os picos de cheias, sobretudo nas áreas impermeáveis (HILTEN et al., 2008).

\section{RETENÇÃO DO ESCOAMENTO COM ADITIVOS}

Além das propriedades físicas na composição dos substratos, o uso de aditivos também são responsáveis por potencializar a absorção de água nas camadas do solo. Em especial, os hidrogéis são utilizados para aumentar tanto no crescimento da vegetação sobre o telhado verde, como na capacidade de retenção ou de disponibilidade de água na planta. No entanto, sua aplicação combinada com o solo depende das características do substrato e das espécies de plantio. Geralmente, esses aditivos apresentam melhores respostas na retenção de água em solos com textura arenosa, ao contrário dos solos argilosos (KOUPAI et al., 2008; AGABA et al., 2010).

Ao estudar o uso de aditivos em telhados verdes na cidade de Melbourne (AUS) de classificação climática $\mathrm{Cfb}$, em taxas de aplicação recomendadas, os aditivos de silicatos obtiveram melhor desempenho que os hidrogéis. Os hidrogéis podem elevar a capacidade de retenção de água ou WHC (water holding capacity), porém não necessariamente elevam o aumento de água 
disponível para a planta ou PAW (plant avaliable water). Correspondente ao potencial matricial, a disponibilidade de água da planta é descrita como a quantidade de água retida no solo entre a capacidade de campo CC e o ponto de murcha permanente PMP (FARREL et al., 2013). Enquanto o parâmetro LAI (leaf area index) é utilizado para caracterizar a área de cobertura verde ou de vegetação e avaliar o efeito térmico sobre os telhados verdes, os parâmetros WHC e PAW representam indicadores de capacidade de retenção. Não somente aplicável quando associado ao uso de aditivos, as mudanças na capacidade de retenção ou nas flutuações de amplitude térmica são percebidas de forma genérica.

A capacidade de retenção do escoamento em telhados verdes diminui à medida que se eleva a intensidade pluviométrica (I), para solos com menor altura de substrato $(\mathrm{H})$ e do parâmetro LAI. Do contrário, quanto maior esses dois parâmetros e menor a intensidade pluviométrica, maior a possibilidade de reter o escoamento (Figura 4).

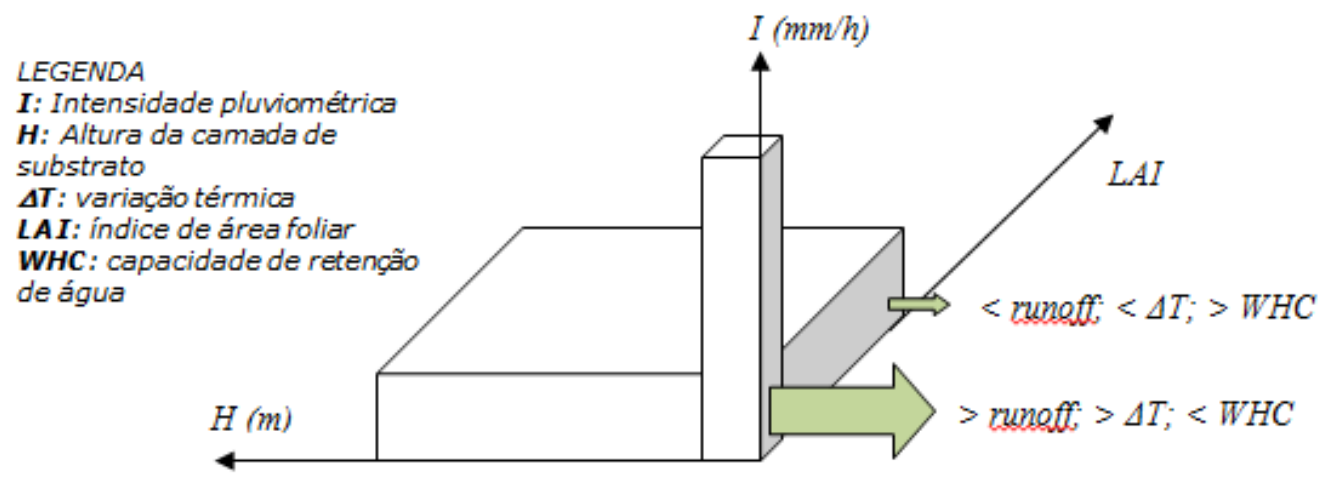

Figura 4 - Influência de parâmetros físicos e climáticos em telhados verdes. Fonte: ALEXANDRI e JONES (2008), ASCIONE, et al. (2013), FARREL et al. (2013), JIM e TSANG (2011), LEE, et al. (2013), MENTENS, et al. (2013), ZHAO et al. (2014). Org. dos Autores).

O conforme térmico, associado às flutuações de temperatura no ambiente interno, pode ser medido de forma genérica inversamente proporcional ao que ocorre com o runoff. Outra condição de bastante influência na retenção do escoamento é a umidade antecedente do solo. Com exceção de poucos trabalhos, como apresentado por MORUZZI et al. (2014), a condição de umidade antecedente não foi critério de avaliação neste artigo em função de poucos dados na análise do solo como da: infiltração acumulada, condutividade hidráulica, grau de saturação e índice de vazios.

\section{CONCLUSÕES}

Ao analisar determinados artigos científicos de telhados verdes situados em mais de 150 países com características climáticas distintas, este estudo permite concluir que:

1. A tipologia construtiva de telhados verdes em edificações urbanas 
apresenta-se como alternativa de microclima em sistemas de arrefecimento de calor e de drenagem de águas pluviais. Profundidades superiores à $10 \mathrm{~cm}$ das camadas de substrato e vegetação, além de declividades não muito acentuadas inferiores à $10 \%$, auxiliam no controle da resistência térmica interna do ambiente e na retenção temporária de volumes de precipitação efetiva observados na cobertura.

2. Sistemas de arrefecimento estão condicionados às condições climáticas locais de modo que climas frios e úmidos do tipo Köppen-Geiger C e D tendem a limitar os efeitos térmicos devido ao potencial evaporativo e de fotossíntese gerado pela vegetação, ainda que haja capacidade de isolamento provocado pela massa térmica de umidade nos telhados verdes.

3. Há relativa influência das classificações climáticas de Köppen-Geiger na capacidade de retenção do escoamento das águas pluviais sobre os telhados verdes. Regiões de climas frios, úmidos ou quentes alteram de forma relativa os volumes de retenção das águas pluviais em telhados verdes. Para aumentar a capacidade de retenção, além da umidade antecedente do solo, recomenda-se analisar os parâmetros: intensidade pluviométrica, altura da camada de substrato, densidade foliar e declividade do telhado.

\section{REFERÊNCIAS}

AGABA, $H$. et al. Effects of hydrogel amendment to different soils on plant available water and survival of trees under drought conditiagaons. Clean-Soil Air Water, v, 38, p. 328-335. 2010.

ALCAZAR S, BASS B. Energy performance of green roofs in a multi storey residential building in Madrid. In: Proceedings of Greening Rooftops for Sustainable Communities, Washington, DC, 2005.

ALEXANDRI, E.; JONES, P. Temperature decreases in an urban canyon due to green walls and green roofs in diverse climates. Building Environmental, v. 43, p. 480-493, 2008.

ALEXANDRI, E.; JONES, P. Developing a one-dimensional heat and mass transfer algo- rithm for describing the effect of green roofs on the built environment: compar- ison with experimental results, Building Environmental, v. 42, 2835-2849. 2007.

ANDRADE, N. C.; RORIZ, M. Comportamento Térmico de Cobertura Verde Utilizando a Grama Brachiaria Humidicola na Cidade de São Carlos, SP. Parc v.1, n.4, p.1-16. 2009.

ASCIONE, F. et al. Green roofs in European climates. Are effective solutions for the energy savings in air-conditioning? Applied Energy, v. 104, p. 845-859, 2013

AYATA, T.; TABARES-VELASCO, P.C.; SREBRIC, J. An investigation of sensible heat fluxes at a green roof in a laboratory setup. Building Environmental, v. 46, p. 1851-1861, 2011.

BERDNTSSON, J.C.; BENGTSSON, L.; JINNO, K. Runoff water quality from intensive and extensive vegetated roofs. Ecological Engineering, v. 35, p. 369$380,2009$. 
CARTER, T.L.; RASMUSSEN, T.C. Hydrologic behavior of vegetated roofs. Journal of the American Water Resources Association, v. 42 (5), p. 1261-1274. 2006.

DEPARTMENT OF ENERGY (DOE) / CE-0335P. Energy Efficiency and Renewable Energy. Assistant Secretary. Radiant barrier attic fact sheet, 1991. Disponível em: <http://www.ornl.gov/sci/roofs+walls/radiant/rb_01.html>. Acesso em $14 / 12 / 2014$.

FARREL, C.; ANG, X.Q.; RAYNER, J.P. Water-retention additives increase plant available water in green roof substrates. Ecological Engineering, v. 52, p. 112118. 2013.

GETTER, K.L.; ROWE, D.B.; ANDRESEN, J.A. Quantifying the effect of slope on extensive green roof stormwater retention. Ecological Engineering, v. 31, p. 225-231, 2007.

GETTER, K.L. et al. Carbon sequestration potential of extensive green roofs. Environmental Science \& Technology, v. 43, p. 7564-7570, 2009.

GREGOIRE, B.G.; CLAUSEN, J.C. Effect of a modular extensive green roof on stormwater runoff and water quality. Ecological Engineering, v. 37, p. p.963969. 2014.

HARPER, G.E. et al. Nine-month evaluation of runoff quality and quantity from an experiential green roof in Missouri, USA. Ecological Engineering, Article in Press, 2014.

HE, H.; JIM, C.Y. Simulation of thermodynamic transmission in green roof ecosys-tem. Ecological Modelling, v. 221, p. 2949-2958. 2010.

HILTEN, R.N.; LAWRENCE, T.M.; TOLLNER, E.W. Modeling stormwater runoff from green roofs with HYDRUS-1 D. Journal of Hydrology, v. 358, p. 288-293. 2008.

HODO-ABALO, S.; BANNA, M.; ZEGHMATI, B. Performance analysis of a planted roof as a passive cooling technique in hot-humid tropics. Renewable Energy, $v$. 39, p. 140-148. 2012.

JIM, C.Y.; TSANG, S.W. Biophysical properties and thermal performance of an intensive green roof. Building Environmental, v. 46, p. 1263-1274, 2011.

KÖPPEN, W. The thermal zones of the Earth according to the duration of hot, moderate and cold periods and of the impact of heat on the organic world. Meteorol. Z. 1, 215-226 (translated and edited by VOLKEN, E. and S. BRÖNNIMANN). Meteorologische Zeitschrift, v. 20, p. 351-360. 2011.

KOTTEK, M.; GRIESER, J.; BECK, C.; RUDOLF, B.; RUBEL, F. World map of the Köppen-Geiger climate classification updated. Meteorologische Zeitschrift, v.15, n.3, p. 259-263, 2006.

KOUPAI, J.A.; ESLAMIAN, S.S.; KAZEMI, J.A. Enhancing the available water content in unsaturated soil zone using hydrogel, to improve plant growth indices. Ecohydrologic Hydrobiology v. 8, p. 67-75. 2008.

LEE, J.Y.; et al. Quantitative analysis on the urban flood mitigation effect by the extensive green roof system. Environmental Pollution, v. 181, p.25 -261, 2013.

LI, J.F. et al. Effect of green roof on ambient $\mathrm{CO} 2$ concentration. Building Environmental, v. 45, p. 2644-2651, 2010. 
LIU, K. Engineering performance of rooftop gardens through field evaluation. In: Proceedings of the RCI 18th International Convention and Trade Show, Tampa, Florida, p. 1-15. March 13-18, 2003.

LOCATELLI, L., MARK, O., MIKKELSEN, P.S., ARNBJERG-NIELSEN, K., JENSEN, M.B., BINNING, P.J. Modelling of green roof hydrological performance for urban drainage applications, Journal of Hydrology, v. 519, p.3237-3248, 2014.

MENTENS, J.; et al. Green roofs as a tool for solving the rainwater runoff problem in the urbanized 21st century? Landscape and Urban Planning, v. 77, p. 217-226, 2006.

METSELLAR, K. Water retention and evapotranspiration of green roofs and possible natural vegetation types. Resources, Conservation and Recycling, v. 64, p. 49-55. 2012.

MITCHELL, T. D.; P. D. JONES. An improved method of constructing a database of monthly climate observations and associated high-resolution grids. International Journal of Climatology, v.25, p. 693-712. 2005.

MORAU, D.; LIBELLE, T.; GARDE, F. Performance Evaluation of Green Roof for Thermal Protection of Buildings In Reunion Island. Energy Procedia v. 14, p. 1008-1016, 2012.

MORUZZI, R.B.; MOURA, C.C. de; BARBASSA, A.P. Avaliação do efeito da inclinação e umidade antecedente na qualidade e quantidade das parcelas escoadas, percoladas e armazenadas em telhado verde extensivo. Ambiente Construído, Porto Alegre, v. 14, n. 3, p. 59-73, jul./set. 2014.

NIACHOU, A. et al. Analysis of green roof thermal properties and investigation of its energy performance. Energy Building, v.33, p. 719-729. 2001.

OHNUMA JR., A.A.; ALMEIDA NETO, P.; MENDIONDO, E.M. Análise da retenção hídrica em telhados verdes a partir da eficiência do coeficiente de escoamento. Revista Brasileira de Recursos Hídricos, v.19, n.2, p. 41-52. 2014.

OULDBOUKHITINE, S.E., BELARBI, R., JAFFAL, I., TRABELSI, A. Assessment of green roof thermal behavior: a coupled heat and mass transfer model, Building Environmental, v. 46, p. 2624-2631. 2011.

PALLA, A.; GNECCO, I.; LANZA, L.G. Unsaturated 2D modelling of subsurface water flow in the coarse-grained porous matrix of a green roof. Journal of Hydrology, v. 379, p. 193-204. 2009.

PITTALUGA, I.; et al. Sound absorption of different green roof systems. 162nd Meeting Acoustical Society of America, San Diego, California, 31 October - 4 November 2011.

RAMIREZ, W.A.; BOLAÑOS-SILVA, T. Revisión sobre el papel de los techos verdes en la remoción de carbono atmosférico en el neotrópico. Revista Nodo, n.12, v.6, ano 6: p.7-18. 2012

RENTERGHEM, T.V.; et al. The potential of building envelope greening to achieve quietness. Building Environmental, v. 61, p. 34-44. 2013.

RUBEL, F.; KOTTEK, M. Observed and projected climate shifts 1901-2100 depicted by world maps of the Köppen-Geiger climate classification. Meteorologische Zeitschrift, v.19, n.2, p.135-141. 2010. 
TASSI, R.; TASSINARI, L. C. da S.; PICCILLI, D. G. A.; PERSCH, C. G. Telhado verde: uma alternativa sustentável para a gestão das águas pluviais. Ambiente Construído, Porto Alegre, v. 14, n. 1, p. 139-154, jan./mar. 2014.

VIJAYARAGHAVA, K.; JOSHI, U.M. Can green roof act as a sink for contaminants? A methodological study to evaluate runoff quality from green roofs. Environmental Pollution, v. 194, p. 121-129. 2014.

VILLARREAL, E.L.; BENGTSSON, L. Response of a Sedum green-roof to individual rain events. Ecological Engineering, v. 25, 1-7, 2005.

WEI, K. Cold Region Building Roof Ecological Design. Xi'An: Xi'An University of Architecture and Technology; 2005.

WONG, NH, CHEONG DKW, YAN H, SOH J, ONG CL, SIA A. The effects of rooftop garden on energy consumption of a commercial building in Singapore. Energy Build, v. 35, p. 353-64. 2003.

ZHAO, M. et al. Effects of plant and substrate selection on thermal performance of green roofs during the summer. Building Environmental, v. 78, p. 199-211, 2014. 